\title{
Doctors on their own when dealing with racism from patients
}

- Cite as: CMAJ 2018 September 17;190:E1118-9. doi: 10.1503/cmaj.109-5633

Posted on cmajnews.com on Aug. 29, 2018.

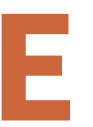
arly in Dr. Cornelia Wieman's career as a psychiatrist, a patient refused to see her because she was Indigenous. "I tried to talk to them, to explain I was qualified, but the patient was adamant," she says. Humiliated, Wieman called an outpatient clinic to send another doctor. "I didn't feel like I had a choice, and even now, 20 years on, I don't know if I would, either."

Doctors who aren't white often face racism at work, but there's little recourse when they do. Medical regulators, professional organizations, schools and institutions don't often have policies and protocols to guide or protect targeted doctors. "Institutions would rather just deal with it individually and quickly, trying to avoid any litigious situations," says Wieman, president of the Indigenous Physicians Association of Canada. Sometimes, "your colleagues and the administrative structure are not really that supportive or culturally safe, either."

This often leaves physicians alone in dealing with patient prejudice. In Ontario, doctors have the right to refuse to treat someone if they feel at risk of harm, but it's unclear how this applies to racist abuse. Refusing to treat a patient may open a doctor to a regulatory complaint. Many physicians simply ignore abuse and keep working, but this also increases their risk of a complaint if something goes wrong. Even transferring patients to a colleague runs the risk of looking like you're unable to cope, Wieman says. "There is still that machismo attitude in medicine, like, you have to buckle down and do the best job and it doesn't matter whether this patient is abusive." Over time, "it can really take a toll on people."

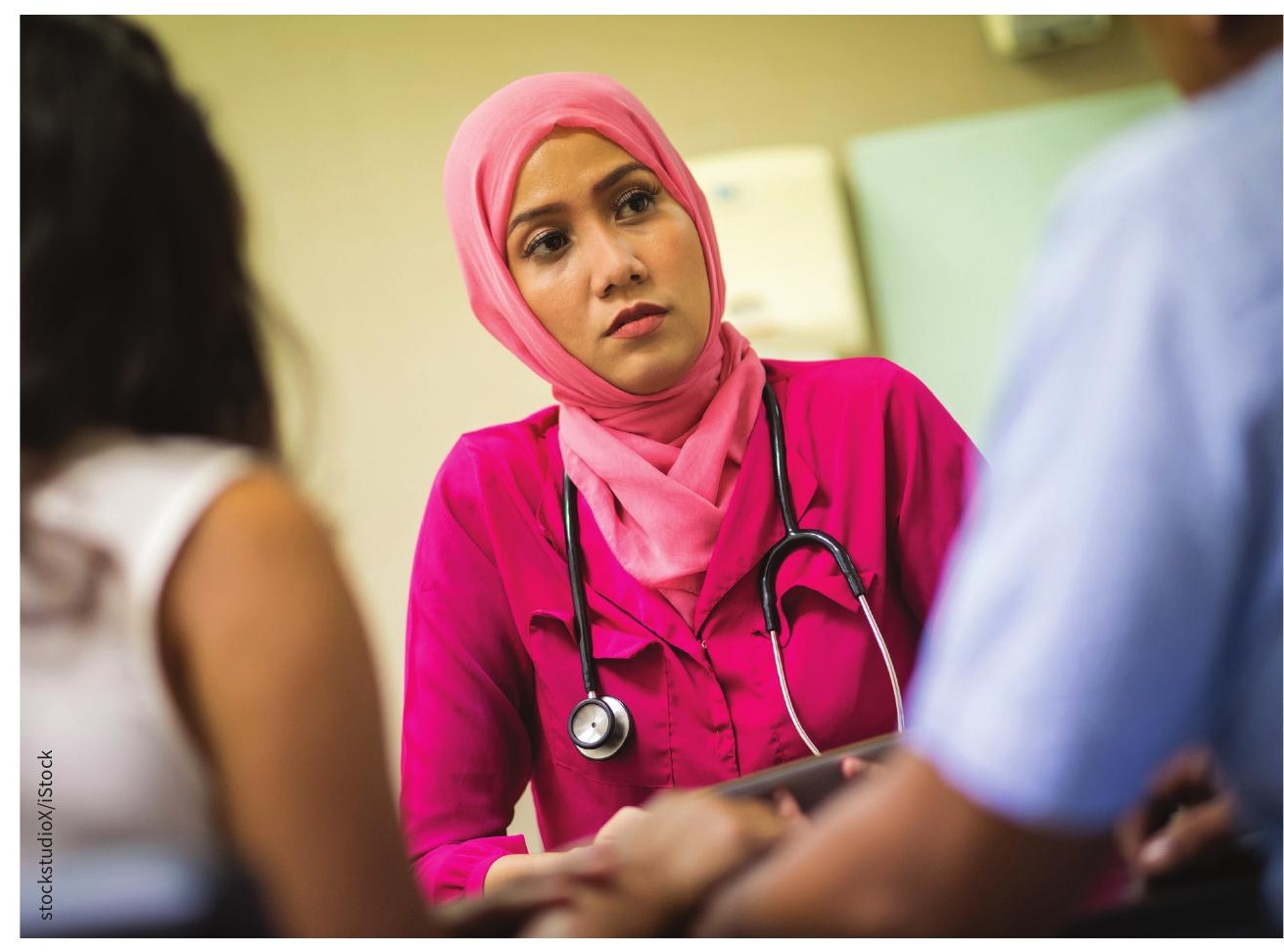

Doctors often experience or witness racism at work but don't often receive guidance or support to deal with it.

There aren't good statistics on the racial makeup of Canada's physician workforce or their experiences of racism. Anecdotally, certain physicians receive more abuse than others, says Dr. Sohail Gandhi, president-elect of the Ontario Medical Association. Recent immigrants, those with accents and those working in larger cities "perhaps have more day-today issues with racist behaviour."

Physician organizations could do a better of job raising awareness about the additional challenges these doctors face, says Gandhi. "It's hard to appreciate if you're not living it." Medical regulators could make the biggest difference by spe- cifically addressing racism in anti-abuse policies, he adds. Physicians need specific guidance to know "it's okay to say this has happened and there's a way of dealing with it that won't get me into trouble."

American organizations are starting to address the problem, but Canada has lagged, says Dr. Kulvinder Gill, president of Concerned Ontario Doctors. One issue is that most medical leaders in Canada are white and may not realize the extent of the racism their non-white colleagues face. In the Greater Toronto Area, for example, only $16 \%$ of hospital senior management and $14 \%$ of hospital board members are not white, compared to $47 \%$ of the general population. 
As a result, organizations often treat incidents of racism that surface in the media as the exception rather than the rule, says Gill. "They put out a few sentences saying that it's not the Canada they know; there's similar wording almost every time, but it doesn't go beyond that."

Institutions should have clear policies on handling racist behaviour and an ombudsman who doctors can turn to when they face abuse, she says. Also, medical schools should train students on how to handle patient prejudice. One survey of American family medicine trainees found that 35\% experienced intimidation based on race, gender or culture during their residencies. "You encounter it at all levels of your training, and it was something that was never discussed," Gill says.

It is also important to have mechanisms for holding patients accountable. According to Dr. Ritika Goel, lead physician at the Inner-City Family Health Team in Toronto, having a code of conduct for both staff and patients can be helpful. The safety of health workers must be balanced with the vulnerability of patients, regardless of their behaviour, she says. Although it may not be possible to refuse a patient care, "the key in these situations is to ensure the situation is acknowledged and directly addressed, rather than being avoided or ignored."

Lauren Vogel, CMAJ 